\title{
Castleman's disease - a case report
}

\author{
Maciej Wilczak ${ }^{1}$, Małgorzata Kampioni, ${ }^{1,2}$ Jacek Szmeja ${ }^{3}$ \\ 1Department of Medical Education, Faculty of Health Sciences, Medical University, Poznan, Poland \\ 2Department of Gynecology and Obstetrics, Clinic of Gynecologic Surgery, Medical University, Poznan, Poland \\ ${ }^{3}$ Department of General Surgery, Gastroenterological and Endocrine, Medical University, Poznan, Poland
}

Videosurgery and other miniinvasive techniques 2011; 6 (1): 27-32 DOI: $10.5114 /$ wiitm.2011.20990

\begin{abstract}
Angiofollicular lymphoid hyperplasia (Castleman's disease) is a very rare disease of lymphatic tissue, manifested by overgrowth of $B$ lymphocytes and plasma cells in lymph nodes. The aetiology of this lymphocyte hyperplasia has not been conclusively explained and its pathogenesis is still not known. There are three types of the disease based on histological criteria: plasma-cell, hyaline-vascular and transitional. Clinically it is classified into two forms, localized and multicentric (disseminated/generalized). Castleman's disease may develop not only in lymph nodes, but also in other organs and tissues, e.g. larynx, pancreas, meninges, etc. In patients with localized Castleman's disease the most important therapy is radical surgery of the tumour, which creates conditions leading to complete recovery. In the case of multicentric diagnosis the prognosis is unsure.

The paper describes an atypical case of Castleman's disease, diagnosed as localized form in the patient's pelvis minor with accompanying cystic changes in the mesocolon.
\end{abstract}

Key words: Castleman's disease, angiofollicular lymphoid hyperplasia, lymph nodal hamartoma, gynaecological surgery.

\section{Introduction}

Angiofollicular lymphoid hyperplasia, commonly known as Castleman's disease, benign giant lymphoma or lymph nodal hamartoma, is a very rare disease of lymphatic tissue, manifested by over-proliferation of B lymphocytes and plasma cells in lymph nodes. The aetiology of this lymphocyte hyperplasia has not been conclusively explained and its pathogenesis is still not known. Some theories of possible immunological or infection basis of the condition were formulated and HHV-8 (Kaposi sarcoma-associated herpesvirus - KSHV), Mycobacterium tuberculosis, Toxoplasma gondii and Epstein-Barr virus [1-4] are among potential pathogens. It seems that the key factor in pathogenesis of this disorder is abnormal production of cytokine interleukin 6 , stimulating $B$ lymphocytes, which results in their intensified pro- liferation and differentiation towards plasma cells [5]. Although Castleman's disease was first described in 1956 by Benjamin Castleman et al. (1956) in 13 patients as enlargement of lymph nodes of unknown aetiology, it is still unclear whether it is one disease or several overlapping disorders of the lymphatic system [6-8].

On the basis of histological criteria three types of the disorder are distinguished: plasma-cell, hyaline-vascular and transitional type $[2,9,10]$. There are two clinical forms, multicentric Castleman's disease (MCD) and localized unicentric Castleman's disease (UCD).

Localized Castleman's disease includes plasmacell type (20\%), occurring mostly in children and young people in the 2 nd-3rd decade of life, often accompanied by changes in blood morphology (anaemia), and hyaline-vascular type (80\%), usually 
benign, typical for patients in the fourth decade of life [11]. Localized form usually concerns one lymph node or a group of nodes with similar localization forming a so-called Castleman's tumour, most often in the mediastinum, retroperitoneal space or axilla. Rarely the tumours may occur in the neck, abdominal cavity, pelvis minor, subcutaneous tissue, salivary glands or muscles [12].

Multicentric form includes hyaline-vascular type occurring in older patients in the 6th-7th decade of life, usually accompanied by disseminated lymphadenopathy, hepatosplenomegaly, thrombocytopenia, anaemia, hypoalbuminaemia, hypergammaglobulinaemia, fever, night sweat, weakness, weight loss, increased level of transaminases and inflammation markers, ascites or pleural exudate [9-11]. Multicentric hyaline-vascular and transitional types are very infrequent. The course of multicentric disease is usually aggressive and the prognosis is unfavourable.

Coexistence of Castleman's disease with Kaposi sarcoma, myasthenia, pemphigus, amyloidosis or POEMS syndrome (polyneuropathy, organomegaly, endocrinopathy, monoclonal proteinaemia and skin changes) has been described in the medical literature $[3,12]$.

Due to the lack of unequivocal clinical criteria, radiological symptoms or biochemical markers, histopathological analysis of specimens or whole changed lymph nodes from the patient is of key importance in the diagnostics of this disease. Fine needle aspiration biopsy (FNAB) of the tumour is definitely less useful in the diagnosis [11].

Primary treatment of unicentric tumours is a surgical resection of the change. If a radical resection is impossible it is recommended to remove as much of the changed tissue as possible [12]. Radiotherapy is used as an adjuvant therapy in this form of the disease.

There is no definite therapeutic regime for multicentric form of Castleman's disease. The therapy may include prednisone, melphalan, interferon $\alpha$ or auramine [12].

The paper describes an atypical case of Castleman's disease, diagnosed as localized form in the patient's pelvis minor with accompanying cystic changes in the mesocolon.

\section{Case report}

The 29-year-old nulliparous patient was admitted to the Operational Gynaecology Department of the Gynaecology and Obstetrics Clinic of Medical University in Poznan on 07.10.2008 with preliminary diagnosis of cystic change in the left ovary. At admission the patient reported paroxysmal abdominal pain, mostly in the area of the left hypogastrium, similar to intestinal colic, occurring for 4-5 years, and dyspareunia. She had a regular menstruation cycle of about 28 days with scanty and painless bleeding. From April to June 2008 she was taking oral contraceptives. Family history of the patient shows that a sister of her father died of liver cancer, the mother of her father died of colon cancer, the grandmother of her father died of lung cancer and the father himself was treated for chronic arterial hypertension.

Due to her trouble the patient had in 2005 a diagnostic laparoscopy that did not reveal any pathologies in the recto-uterine pouch (pouch of Douglas) and pelvis minor, and chromotubation confirmed bilateral patency of uterine tubes.

Manual vaginal examination with a speculum performed at admission revealed a small, well-formed vaginal part and smooth disc of the vaginal part of the cervix with small round ostium. Vaginal secretion was normal, appropriate to the phase of the sex cycle. Bimanual gynaecological palpation showed vagina of average length and width, formed vaginal part directed at the sacral bone. Body of the uterus anteflexed, small, movable, without changes in palpable examination. Right adnexa impalpable. Left adnexa sensitive, with movable, cystic resistance about $5 \mathrm{~cm}$ in diameter.

Transvaginal sonography revealed: anteflexed body of the uterus with AP dimension of $4.7 \times 2.8 \mathrm{~cm}$ and homogeneous $6 \mathrm{~mm}$ thick endometrium. Right ovary $3.0 \times 2.0 \mathrm{~cm}$, with small follicles and normal sonographic structure. Left ovary $2.5 \times 1.5 \mathrm{~cm}$ with similar sonographic structure, without pathological features. Behind uterus and on the left in the recto-uterine pouch a conglomerate of cystic changes $7.0 \times 3.0 \mathrm{~cm}$, possibly corresponding to paraovarian cysts, was observed.

The results of the laboratory test are presented in Table I, biochemical parameters in Table II, and results of the coagulation test in Table III.

Urine analysis revealed the presence of numerous bacteria, 1-3 fresh leucocytes and erythrocytes in the examination field. No protein in urine was observed.

Based on the results of performed tests the patient was qualified for scheduled laparoscopy, to 
Table I. Results of laboratory tests

\begin{tabular}{|c|c|c|}
\hline Tested parameter & Value & Reference values \\
\hline Leucocytes $\left[\times 10^{3} \mu \mathrm{l}\right]$ & 6.79 & $3.5-12.00$ \\
\hline Erythrocytes $\left[\times 10^{6} \mu l\right]$ & 4.30 & $3.5-5.00$ \\
\hline Haemoglobin [g/dl] & 11.50 & $11.00-15.20$ \\
\hline Haematocrit [\%] & 36.4 & $32.0-44.5$ \\
\hline Mean corpuscular volume [fl] & 84.70 & $76.00-98.00$ \\
\hline $\begin{array}{l}\text { Mean corpuscular } \\
\text { haemoglobin [pg] }\end{array}$ & 26.7 & $25.0-34.0$ \\
\hline $\begin{array}{l}\text { Mean corpuscular haemoglobin } \\
\text { concentration }[\mathrm{g} / \mathrm{l}(\mathrm{L})]\end{array}$ & 31.6 & $32.2-36.8$ \\
\hline Thrombocytes $\left[\times 10^{3} \mu \mathrm{ll}\right]$ & 240.0 & $140.0-440.0$ \\
\hline Lymphocytes [th/ul] & 1.4 & $1.00-3.50$ \\
\hline Monocytes $[$ th $/ \mu \mathrm{l}]$ & 0.7 & $0.2-1.0$ \\
\hline Neutrophils $[$ th/ $\mu \mathrm{l}(\mathrm{H})]$ & 6.9 & $2.0-6.5$ \\
\hline Eosinophils $[$ th $/ \mu l]$ & 0.0 & $0.0-0.5$ \\
\hline Basophils [th/ $\mu \mathrm{l}]$ & 0.1 & $0.0-0.1$ \\
\hline Percentage of lymphocytes [\% (L)] & 15.8 & $25.0-40.0$ \\
\hline Percentage of monocytes [\%] & 7.4 & $3.10-8.70$ \\
\hline Percentage of neutrophils [\% $(\mathrm{H})$ ] & 75.9 & $48.7-70.1$ \\
\hline Percentage of eosinophils [\%] & 0.4 & $0.3-5.4$ \\
\hline Percentage of basophils [\%] & 0.6 & $0.2-1.2$ \\
\hline
\end{tabular}

which she agreed in writing after talking to her attending physician.

The surgery was performed on 08.10.2008. After inserting a laparoscope in a typical manner into the patient's abdomen, the small, movable body of the uterus was observed and in the area of the right horn and on the posterior wall of the body a myoma $10 \mathrm{~mm}$ in diameter was spotted, which was then enucleated (Figure 1). Adnexa bilaterally unchanged in macroscopic examination. In the recto-uterine pouch a multilocular, cystic change coming from the mesocolon was found. After consultation with the head of the Operative Gynaecology Department further consultation and surgical assistance was asked for and the surgery became a longitudinal, median laparotomy from the pubic symphysis to the
Table II. Biochemical parameters

\begin{tabular}{|lcc|}
\hline Tested parameter & Value & Reference values \\
\hline Sodium in serum [mmol/l] & 135.7 & $135.0-145.0$ \\
\hline Potassium in serum [mmol/l] & 4.1 & $3.7-4.9$ \\
\hline Chlorides in serum [mmol/l] & 104.4 & $97.0-107.0$ \\
\hline Urea [mg/dl] & 22.00 & $17.00-43.00$ \\
\hline Creatinine [mg/dl] & 0.83 & $0.66-1.09$ \\
\hline Uric acid [mg/dl] & 2.5 & $2.6-6.0$ \\
\hline Aspartate aminotransferase [U/l] & 16.0 & $0.0-31.0$ \\
\hline Alanine aminotransferase [U/l] & 10.0 & $0.0-34.0$ \\
\hline Total cholesterol [mg/dl] & 187.00 & $130.0-200.0$ \\
\hline HDL cholesterol [mg/dl] & 65.5 & $40.0-80.0$ \\
\hline Triglycerides [mg/dl] & 63.00 & $30.0-150.0$ \\
\hline LDL cholesterol [mg/dl] & 109.00 & Less than 150.00 \\
\hline
\end{tabular}

Table III. Results of coagulation tests

\begin{tabular}{|lcc|}
\hline Tested parameter & Value & Reference values \\
\hline INR & 1.04 & $0.80-1.20$ \\
\hline Prothrombin time [sec] & 13.2 & $9.60-14.40$ \\
\hline Prothrombin index [\%] & 90.90 & $80.0-120.0$ \\
\hline Kaolin-kephalin time (APTT) [sec] & 35.70 & $27.3-40.90$ \\
\hline Fibrinogen [mg/dl (H)] & 864.5 & $180.0-350.0$ \\
\hline Anti-thrombin III [\%] & 86.7 & $75.0-125.0$ \\
\hline
\end{tabular}

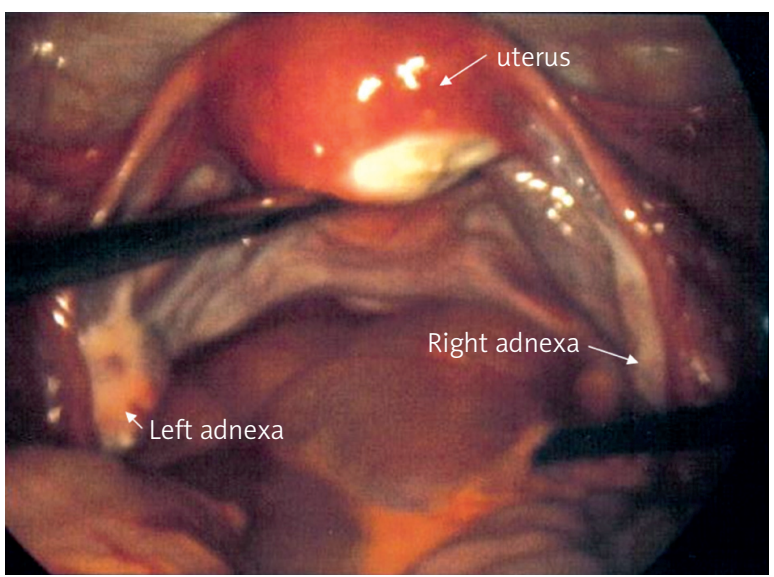

Figure 1. Endoscopic imaging of uterus with bed after removal of myoma of posterior wall and adnexa 
navel. During the surgery a cyst of the mesocolon filled with clear fluid was found and entirely removed (Figures 4, 5). About $10 \mathrm{~cm}$ above the cyst another tumour of dimensions $8 \times 6 \mathrm{~cm}$ was observed. It was infiltrating the intestine wall and its structure corresponded to lymph node (Figure 2). The tumour was entirely removed and sent for intraoperative histopathological analysis, and intestinal bilateral end-to-end anastomosis was performed by means of interrupted suture (Figure 3). Other organs of the abdominal cavity were examined and the only deviations were enlarged, palpable lymph nodes in the mesentery. Peritoneal lavage was carried out and the pouch of Douglas was drained. Intraoperative examination brought the following results: simple cyst of mesocolon (first specimen) and lymph node - probably lymphatic leukaemia (second specimen). The final result of histopathological examination of the specimen con-

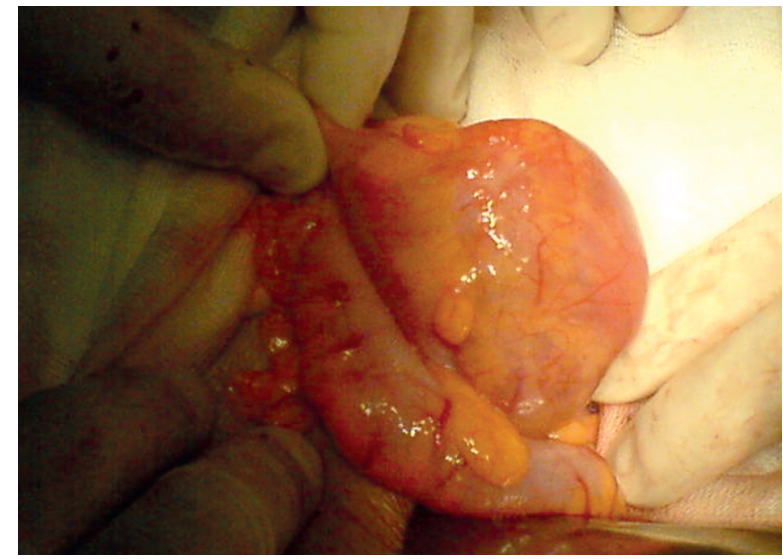

Figure 2. Tumour of descending colon

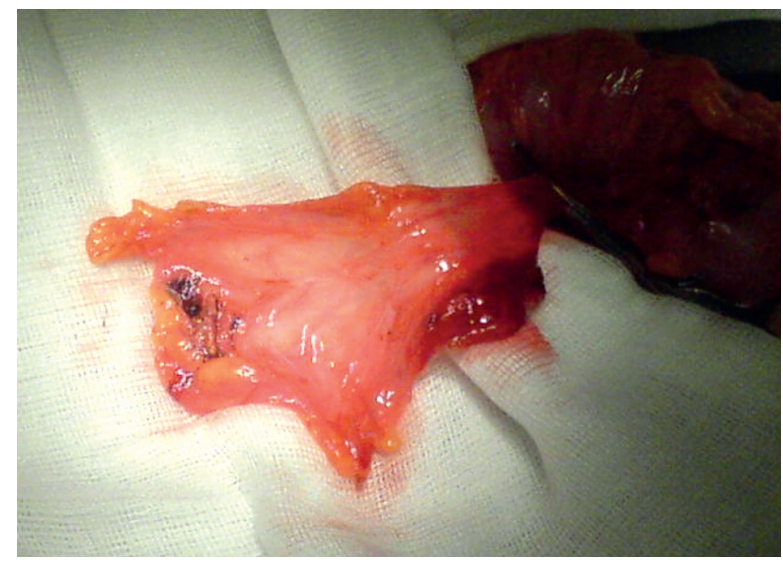

Figure 3. Dissected tumour of descending colon firmed the presence of enlarged lymph nodes, and Castleman's disease exponents of plasma-cell type. This diagnosis was ascertained by immunohistochemical tests: CD20+++ (within over-proliferative follicles), CD3+++ (in interfollicular zone), CD10+ (within follicles), bcl-2+++ (around follicles), Ki67++ (inside follicles), CD79a+++ (within follicles); plasma cells were of polyclonal character - they produced both lambda and kappa chains.

Due to the systemic form of the disease with generalized lymphadenopathy and possibility of additional symptoms (fever, anaemia, increased ESR, hypergammaglobulinaemia), the patient after haematological check-up was referred for further haematological therapy and supervision.

At present the patient is being monitored in an outpatient clinic, haematological and general parameters are regularly checked, and no other systemic treatment was introduced.

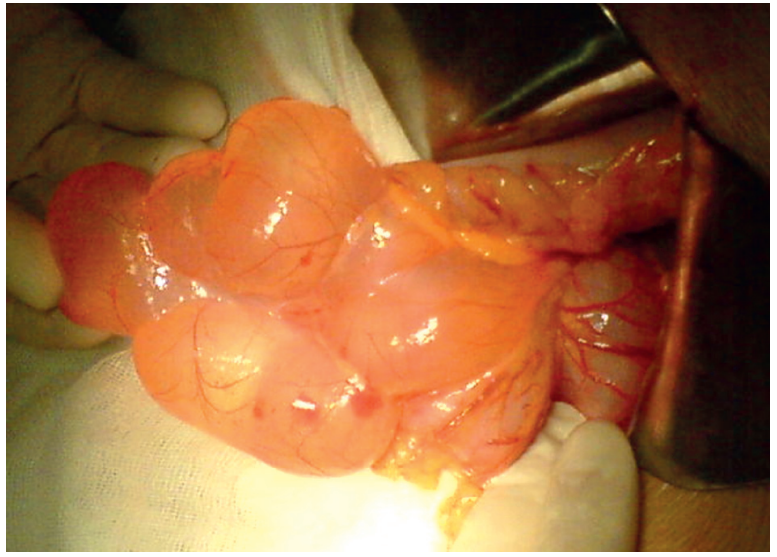

Figure 4. Cysts of mesocolon - mesosigmoid

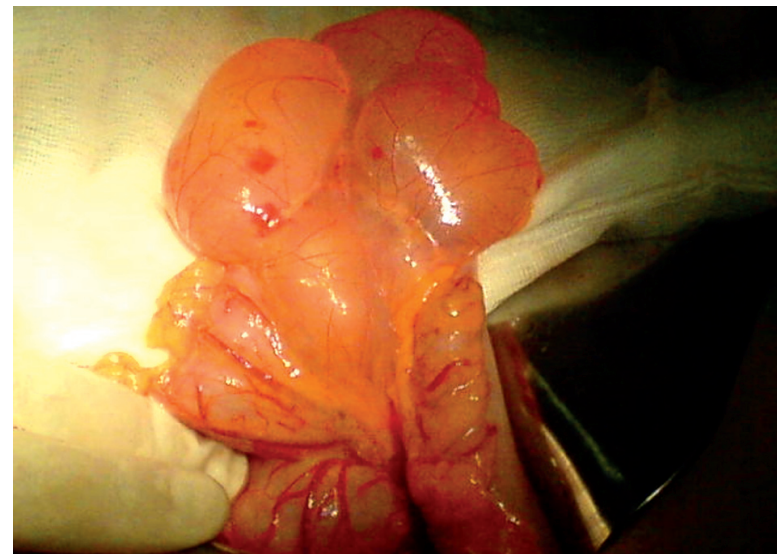

Figure 5. Cysts of mesocolon - mesosigmoid 


\section{Discussion}

Castleman's disease is a very rare proliferative disease of the lymphatic system with unclear aetiology. Due to the low specificity of its symptoms and the necessity of histological verification of tissue specimens taken from the patients, its early detection and correct diagnosis are very difficult. It occurs more often in patients with immunity disorders (suffering from AIDS), young people in the 2 nd-3rd decade of life, and it is mostly diagnosed as the localized form. Castleman's disease may develop not only in lymph nodes but also in other organs and tissues, e.g. larynx, pancreas, meninges [13].

This article describes a clinical case of a patient treated in a gynaecological and obstetric clinic because of paroxysmal abdominal pain, mostly in the area of the left hypogastrium, similar to intestinal colic, occurring for 4-5 years, dyspareunia and primary infertility. Laboratory tests, interview and physical and clinical examinations confirmed the presence of tumour in the pelvis minor. It is well-known that the most frequent location of Castleman's disease is the mediastinum (63\%), then the retroperitoneal space (11\%) and axial lymph nodes (4\%) [14-21]. Occurrence of Castleman's tumour in localized form of the disease in the alimentary tract, colon or stomach is exceptionally rare. In the described case the tumour, $8 \times 6 \mathrm{~cm}$ in size, was infiltrating the wall of the sigmoid colon.

The symptoms reported by the patient during the interview at admission are not typical. Hypogastric pains may occur in many gynaecological and gastroenterological disorders. Dyspareunia appears in patients with chronic inflammatory states in the pelvis minor or reproductive organ but it is not the only case. It is also found in women with irritable colon or chronic inflammation of the urinary tract. From the clinical point of view the specificity of the complaints reported by the patient is hardly characteristic.

Deviations of laboratory tests included slightly lower mean corpuscular haemoglobin concentration, increased level in blood and the percentage of neutrophils in peripheral blood smear, and increased fibrinogen concentration. Decreased percentage of lymphocytes in peripheral blood smear was characteristic. The presented changes from the laboratory results have not been described previously in the literature. Only in the case reported by Kycler et al., but referring to the generalized form of Castleman's dis- ease, were there described anaemia, lymphopenia and coagulation disorders, such as elevated concentration of D-dimers and fibrinogen, being the results of systemic disorders accompanying the disease [22]. Moreover, anaemia is mentioned as a frequent disorder in plasma-cell type of Castleman's disease, which was also confirmed in the case of our patient [11].

It seems that there are no specific laboratory markers or clinical symptoms that may make the attending physician suspect Castleman's disease.

Other symptoms, typical for generalized form of the disease, such as disseminated lymphadenopathy, hepatosplenomegaly, thrombocytopenia, hypoalbuminaemia, hypergammaglobulinaemia, fever, night sweat, weakness, weight loss, increased level of transaminases and inflammation markers, ascites or pleural exudates were not observed in our patient.

In the case of localized Castleman's disease the most important therapy is radical surgery of the changes, which may lead to complete recovery [20, 22, 23]. Prognosis in these situations is favourable. However, diagnosis of Castleman's disease requires additional diagnostic tests to be performed, aimed at excluding other foci of the disease or complications from internal organs, e.g. renal failure resulting from amyloid accumulation or pancreatitis. Some clinicians claim that analysis of IL-6 level is justifiable in patients suffering from the disease, as elevated concentration of this cytokine may be a signal for introducing systemic therapy protecting the patients from systemic complications [22].

Patients with diagnosed Castleman's disease should undergo medical supervision, periodic imaging examinations and IL-6 level analysis. It is also important to exclude the presence of neoplastic diseases in these patients, as the literature describes a tendency to coexistence of those disorders [23-27].

\section{Conclusions}

1. Angiofollicular lymphoid hyperplasia is a very rare disease of lymphatic tissue, manifested by overproliferation of $B$ lymphocytes and plasma cells in lymph nodes, and its aetiology and pathology are not well known.

2. Localized form usually concerns one lymph node or a group of nodes with similar location forming a so-called Castleman's tumour, most often in the mediastinum, neck or axilla. Rarely the tumours may be located in other areas, as reported in this 
article, namely the retroperitoneal space, abdominal cavity, pelvis minor, subcutaneous tissue, salivary glands or muscles.

3. In the case of localized Castleman's disease the most important therapy is radical surgery of the changes, which may lead to complete recovery. Prognosis for multicentric form of the disease is unsure.

\section{References}

1. Frizzera G. Castleman's disease: more questions than answers. Hum Pathol 1985; 16: 202-5.

2. Keller AR, Hochholzer L, Castleman B. Hyaline-vascular and plasma-cell types of the mediastinum and other locations. Cancer 1972; 129: 670-83.

3. Palestro G, Turrini F, Pagano M. Castleman`s disease. Adv Clin Path 1999; 3: 11-22.

4. Samoszuk M, Ramzi E, Ravel J. Disseminated persistent lymphoid hyperplasia containing Epstein-Barr virus and clonal rearrangements of DNA. Diagn Mol Pathol 1993; 2: 57-60.

5. Łukaszewicz M, Mroczko B, Szmitkowski M. Znaczenie kliniczne interleukiny 6 (IL-6) jako czynnika rokowniczego w chorobie nowotworowej. Pol Arch Med Wewn 2007; 117: 247-51.

6. Castleman B, Iverson L, Mendez VP. Localized mediastinal lymphnode hyperplasia resembling thymoma. Cancer 1956; 9: 822-30.

7. Castleman B, Towne VW. Hyperplasia of mediastinal lymph nodes. Case 40011. N Eng J Med 1954; 250: 26-30.

8. McCarty MJ, Vukelja SJ, Banks PM, Weiss RB. Angiofollicular lymph node hyperplasia (Castleman's disease). Cancer Treat Rev 1995; 21: 291-310.

9. Casper C. The aengiology and management of Castleman disease at 50 years: translating pathophysiology to patient. $\mathrm{Br}$ J Haematol 2005; 129: 3-17.

10. Herrada J, Cabanillas F, Rice L, et al. The clinical behavior of localized and multicentric Castleman disease. Ann Intern Med 1998 128: 657-62.

11. Kaczmarczyk D, Zimmer-Nowicka J, Jesionek-Kupnicka D, et al. Choroba Castlemana. Opis przypadku. Otolaryngolog Pol 2008; 5: 621-4.

12. Kaniewska M, Wasielica-Berger J, Wereszczyńska-Siemiątkowska U, et al. Choroba Castlemana naśladująca guz trzustki - trudności diagnostyczne. Przegl Gastroenterol 2007; 2: 199-204.

13. Szmeja Z, Obrębowski A, Burian P. A case of laryngeal localization of a so-called Castelman tumor. HNO 1984; 32: 252-45.

14. Gaunt GA, Gostout BS, Remstein E, Cliby WA. Pelvic Castleman disease presenting as vaginal occlusion. Obstet Gynecol 2002; 100: 1082-5.

15. Goetze O, Banasch M, Junker K, et al. Unicentric Castleman disease of the pancreas with massive central calcification. World J Gastroenetrol 2005; 11: 6725-7.

16. Kim KN, Lee KN, Kang MJ, et al. Hyaline vascular type Castleman disease presenting as an esophageal submucosal tumor: case report. Korean J Audiol 2006; 7: 73-6.

17. Malaguarnera M, Restuccia N, Laurino A, et al. Extralymphonodal Castleman's disease. A case report. Panminerva Med 1999; 41 363-6.
18. Rark KS, Choi YJ, Song KS. Hyaline-vascular type Castleman's disease involving both orbits. Acta Ophthalmol Scand 2002; 80: 537-9.

19. Seo BK, Oh YW, Cho KR, et al. Imaging findings of Castleman's disease localized in the axila: a case report. Korean J Radiol 2002; 3: 136-9.

20. Sotrel A, Castelleano-Sanchez AA, Prusmack C, et al. Castleman`s disease in child presenting with a partly mineralized solitary meningeal masses. Pediatr Neurosurg 2003; 38: 232-7.

21. Tan TY, Panh P, Goh KC, et al. Castleman's disease of neck: a description of four cases on contrast-enhanced CT. Br J Radiol 2004; 77: 253-6.

22. Kycler W, Bręborowicz J, Nyczak E, et al. Choroba Castlemana w obrębie szyi oraz przestrzeni zaotrzewnowej - opis przypadków. Współczesna Onkologia 2007; 11: 399-403.

23. Bruzgielewicz A, Hamera-Słynarska M, Osuch-Wójcikiewicz E, et al. Choroba Castlemana - opis przypadku. Otolaryngol Pol 2007; 6: 55-9.

24. Peterson BA, Frizzera G. Multicentric Castleman disease. Semin Oncol 1993; 20: 636-47.

25. Tanda F, Massarelli G, Costanzi G. Multicentric giant lymph node hyperplasia: An immunohistochemical study. Hum Pathol 1993; 14: 1053-8.

26. Wengrower D, Gibson E, Okon E, Golin E. Gastrointestinal manifestation in Castleman disease. Am J Gastroenterol 1990; 85: 79-82.

27. Zamir A, Praer G, Moukarzel AA, et al. Castleman's disease: a rare cause of hematemeis. J Pediatr Gastroenterol Nutr 1999; 28: $112-5$. 